(C) 2021, The Authors. Published by Elsevier Inc. and Fass Inc. on behalf of the American Dairy Science Association ${ }^{\circledR}$. This is an open access article under the CC BY-NC-ND license (http://creativecommons.org/licenses/by-nc-nd/4.0/).

\title{
Danish dairy farmers' acceptance of and willingness to use semen from bulls produced by means of in vitro embryo production and genomic selection
}

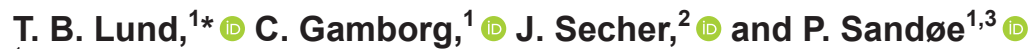 \\ ${ }^{1}$ Department of Food and Resource Economics, University of Copenhagen, Frederiksberg C 1958, Denmark \\ ${ }^{2}$ Department of Veterinary Clinical Sciences, University of Copenhagen, Frederiksberg C 1870, Denmark \\ ${ }^{3}$ Department of Veterinary and Animal Sciences, University of Copenhagen, Frederiksberg C 1870, Denmark
}

\begin{abstract}
A novel technology combining in vitro production and genomic embryo selection is currently under development in dairy cattle breeding. Adoption of this technology will probably accelerate genetic progress toward the main breeding goals of economic interest, as well as allow selection for traits of societal concern such as decreased methane emissions and improved animal welfare. However, dairy farmers, and especially organic farmers, could find the technology morally questionable and reject its use. This cross-sectional study surveyed Danish dairy farmers' general acceptance of the combined technology and their reported likelihood of using semen produced with it. Drawing on diffusion theory, a questionnaire was developed to examine the way farmers discover and communicate about new technological breeding options, and to measure the factors which predict acceptance and likelihood of adopting the technology. The questionnaire was sent to a randomly selected sample of organic and conventional dairy farmers in Denmark, and 85 organic and 71 conventional farmers (41\% response rate) completed it. Seventy-six percent of farmers reported that they would be likely to use semen from bulls derived from the technology. A majority (61\%) also found the technology acceptable, but many (33\%) were unsure or undecided. Most farmers saw the technology as beneficial, but ethical reservations were aired by around a fifth of the farmers. There were no differences between organic and conventional farmers in likelihood of using, perceived utility, and ethical reservations about the technology. Self-reported idealistic organic farmers showed lower acceptance of the technology, but reported similar likelihood of using semen produced by it. Young farmers (20-39 yr) exhibited higher acceptance of the technology. Larger producers (in terms of number of cows) were more likely to report that they will use and accept the technology. We con-
\end{abstract}

Received July 28, 2020.

Accepted March 6, 2021.

*Corresponding author: tblu@ifro.ku.dk clude that it is likely that semen from the technology combining in vitro production and genomic selection would be widely used by both organic and conventional farmers provided that costs can be kept low, and that there are advantages in terms of achieving breeding goals. Structural developments, growth in size of dairy farms, acceptance by young farmers, and the fact that economic incentives (and even ethical arguments) seem to favor the technology all point to this conclusion.

Key words: biotechnology, farmer perception, technology adoption, genomic selection

\section{INTRODUCTION}

Genomic selection (GS) has revolutionized dairy cattle breeding, with its better accuracy, faster trait refinement, and the ability to select on multiple traits (Schaeffer, 2006). It is currently being combined with various reproductive technologies where there is huge potential to improve genetic gains (Humblot et al., 2010; Ponsart et al., 2013; Kasinathan et al., 2015). Even though commercial transfer of bovine genotyped embryos does exist, this technology is still rare or nonexistent in most countries (Viana, 2019), and most dairy farmers to date have no or limited access to it. Nevertheless, ongoing efforts to develop products where GS is combined with ovum pick-up (OPU) and in vitro production of embryos (IVP) (Wrenzycki, 2018) could create wider uptake.

In this paper, the technological combination of OPU and IVP and genomic selection will be referred to as the OPU-IVP-GS technology. This combination is a potential example of how improved genetic gains can be achieved by the combination of reproductive technologies and GS (Humblot et al., 2010; Wrenzycki, 2018) in dairy cattle (Ponsart et al., 2013; Thomasen et al., 2016). Because OPU is technically possible in very young heifers that are not yet sexually mature, this specific technology could also shorten the generation interval. The genetic progress involved in the combination of reproductive technologies and GS (such as OPU-IVP-GS) could not only help farmers regarding 
their main breeding goals of economic interest, but may also help in the selection for traits of societal concern such as decreased methane emissions (de Haas et al., 2017) and improved animal welfare (e.g., by breeding polled animals so that dehorning can be avoided; Windig et al., 2015).

Despite these advantages, some may caution against rapid adoption of the OPU-IVP-GS technology. Other techniques promising to accelerate genetic progress in farm animals such as genetic modification and cloning are morally contested by consumers, as they are seen as unnatural, and there are concerns that they present risks to human and animal health as well as the environment (Brooks and Lusk, 2011; Frewer et al., 2013; Frewer, 2017). Today, companies provide cloning services to livestock producers and breeders in North and South America, Australia, and China. However, in Europe, costs, burdensome regulatory processes, and public concerns have limited the use of farm-animal cloning (Walton, 2018). Indeed, in Denmark, cloning of farm animals for agricultural purposes is prohibited (Miljø- og Fødevareministeriet, 2014).

Given the speed with which the genetic changes are likely to occur, the OPU-IVP-GS technology could also raise concerns about unintended effects on animal welfare (Mark and Sandøe, 2010). Specific problems with large offspring syndrome that can give rise to difficult births and other negative effects on the welfare of both the mother and the offspring (Behboodi et al., 1995; Hansen, 2020) have been recorded in IVP offspring. Some OPU-IVP-GS breeding programs plan to use oocytes from very young heifers for IVP, even though the consequences of oocyte aspiration have only been examined in cows (Chastant-Maillard et al., 2003). This may create concerns about heifer welfare. On the other hand, because no gene editing or any other form of genetic modification is involved in the OPU-IVP-GS technology, this particular combination of techniques may instead simply be viewed as a continuation of traditional selective breeding practices (Coles et al., 2015).

New genetic modification technologies and animal cloning are restricted by extensive regulation, and organic farmers in Europe are not permitted to use embryo transfer as a reproductive technique (European Union, 2007). However, AI with semen from any kind of breeding system (also systems relying on IVP and GS) can so far be used without restriction by organic farmers in Denmark and other EU countries (European Union, 2007). Therefore, apart from issues of price and efficiency, the main factor in uptake of the technology will be farmer acceptance. This acceptance has not yet been investigated. The most recent studies of dairy farmers focus on acceptance of earlier breeding innovations such as AI (Kaaya et al., 2005; Khanal et al.,
2010; Howley et al., 2012) and sexed semen and embryo transfer (Khanal et al., 2010).

The present study examines Danish dairy farmers' general acceptance of the OPU-IVP-GS technology as well as their likelihood of using semen produced using OPU-IVP-GS. As a case study, we use a current Danish research program aiming to develop a product portfolio of semen and embryos based on the technology (see Materials and Methods for details). The study draws on diffusion theory - a theory specifically developed to explain the adoption of technology in agricultural systems (Ryan and Gross, 1943; Rogers, 2003). Diffusion theory suggests that the communication channels through which information spread influence farmers' decisions to adopt a novel technology. Communication channels include nonpersonal information sources (Dan et al., 2019) and interpersonal communication (Rogers, 2003). In general, adoption of novel technologies increases with more communication with agents who are trusted, represent specialized resource systems, and promote innovations. Adoption also increases with obtainment of information from specialist sources (Rogers, 2003). Studies of dairy farmers have also found this relation between adoption and communication channels (Diederen et al., 2003; Brown and Roper, 2017).

We aimed to identify the extent to which Danish dairy farmers attain information about breeding from specialist sources that are likely to promote semen from the OPU-IVP-GS technology (i.e., breeding consultants). We hypothesized that more frequent communication with consultants would be positively associated with acceptance of, and use of semen from, the technology, following the assumptions laid out in earlier studies (Diederen et al., 2003; Brown and Roper, 2017). Further, diffusion theory points out that characteristics of the innovation itself can promote or inhibit adoption: the innovation must be perceived as being better than former tools and technologies (relative advantage); compatible with values, beliefs, and needs (compatibility); and be relatively easy to use and understand (complexity). Further, adoption increases if it is possible to experiment with the innovation on a limited basis (trialability) and if the effect of the innovation is visible to the users (observability; Rogers, 2003).

Among the above-mentioned characteristics, we focused on 2: (1) relative advantage (which we will refer to as perceived utility because the technology is not yet on the market) and (2) compatibility with values and beliefs (which we will refer to as ethical reservations). We expect that the last 3 characteristics (complexity, trialability, and observability) cannot be realistically studied yet because the OPU-IVP-GS technology is not fully developed nor marketed. We hypothesized that perceived utility is positively associated, and ethical 
reservations negatively associated, with farmers' acceptance of and willingness to use semen produced based on the technology.

In addition, diffusion theory (Rogers, 2003) and the wider literature (Olum et al., 2019) suggest that individual farm characteristics will influence whether innovations are adopted and with which speed (Rogers, 2003). We hypothesized that farmers with larger farms and younger farmers would be more likely to adopt the OPU-IVP-GS technology compared with smaller farms and older farmers, in line with Diederen et al. (2003), Khanal et al. (2010), and Olum et al. (2019). We further hypothesized that farmers currently using modern breeding technologies (such as genetic selection, sexed semen, and embryo transfer) would be more likely to adopt and accept the technology. Finally, we hypothesized that self-reported idealistic organic farmers would be more critical of the OPU-IVP-GS technology than other farmers, and that they would be less likely to use semen from this technology. This is based on literature (Verhoog, 2003) that suggest that organic farmers may ascribe importance to the original principles of organic farming, which, among other things, stresses de-industrialization and respect for nature.

\section{MATERIALS AND METHODS}

\section{Participants}

This is an observational study that used crosssectional questionnaire data collected October through December of 2019. From a database consisting of all registered dairy farms in Denmark with at least 40 heifers and dairy cows, a gross sample of 400 farms, divided into 200 organic and 200 conventional farms, was randomly selected (using www.rand.org/integer-sets/). This is a disproportional stratified sampling procedure that overrepresented organic farms, which represented approximately $15 \%$ of dairy farms in Denmark. This enabled comparison of the 2 groups (i.e., organic and conventional farmers) with statistical power to detect differences between them at the medium-effect size level, provided that at least 128 responses (64 in each group) were reached (Hibberts et al., 2012).

The 400 farms were invited via postal mail. The invitation included a password to a website where the questionnaire could be filled out. Alternatively, farmers could request a paper-and-pencil version. Two reminders were sent to the farms by mail. Finally, farms that had not completed the questionnaire after postal contact were then contacted by telephone. They were reminded about the survey and given the opportunity to respond on the telephone.

\section{Measures}

There were no validated questionnaire measures that covered the main constructs of this study. Therefore, the questionnaire (see final version in Supplemental File S1; https://figshare.com/articles/online_resource/ SUPPLEMENTAL_FILE_S1_pdf/14387345) was developed by the authors on basis of their knowledge of the field and prior experience with questionnaire construction. Further, preliminary qualitative interviews with 14 Danish dairy farmers informed the questionnaire construction, and a questionnaire pretest (Collins, 2003) was also conducted. The 14 qualitative interviews were carried out using a semistructured interview guide that aimed to obtain open accounts of the farmers' breeding practices (including breeding choices, priorities, and communication channels) and attitudes/concerns about the OPU-IVP-GS technology (the technology was presented using a prototype of Figure 1). A purposive sampling strategy, quota sampling (Robinson, 2014), was used to ensure that farms of different sizes (at least 3 farms each for small, medium, and large farms), and from different areas of Denmark (at least 5 farms each from East and West Denmark), were included. After 14 interviews, a saturation point (Robinson, 2014) had been reached, meaning that no new information emerged. Using thematic analysis, we used the accounts from the interviews to formulate the questionnaire questions and responses in ways that reflected the dairy farmer's language and frame-of-mind, and to construct questions and response options about breeding practices, interpersonal communication, and information sources that appeared in the interviews. A pilot questionnaire was set up online, and then pretested on 5 farmers (small and large farms, and organic/conventional farmers were included) using a mixture of "think-aloud" and probing questions (Collins, 2003). Probing questions focused on the farmers' understanding of the OPU-IVP-GS technology, and whether the questions about it were covering their thoughts sufficiently. The pretest resulted in deletion of a few questions that did not work well, reformulation of some questions and instructions, and amending the setup and instructions to improve the response flow and comprehension. The 19 farmers that participated in the qualitative interviews or pretests were excluded from the random sampling used for the questionnaire study.

The questionnaire prompted for demographic details (age, geographical region) and farm-specific information (organic/conventional, farm size measured as number of cows). Organic dairy farmers were asked why they had chosen this production mode - distinguishing between idealistic, economic reasons, or a mixture of 
the two. We did this by asking, "When one chooses to have an organic farm, it can be driven by various reasons, including so-called idealistic reasons (e.g. sustainable environment, better treatment of the animals) and so-called economic reasons (e.g. good future prospects for organic consumption and the list price). What is the reason why you originally chose to run or convert to an organic farm?" We used this question to separate self-reported idealistic organic farmers. Fifteen percent (95\% CI: 9-25) of the organic farmers were self-reported idealistic organic farmers. This amounts to $2.2 \%$ (95\% CI: 1.3-3.7) of all dairy farmers in Denmark. The majority of organic farmers (i.e., $74 \%$; $95 \%$ CI: $64-83$ ) stated that they chose organic production because of a combination of economic and idealistic reasons. Analysis (not reported) showed that this subgroup did not differ from conventional farmers regarding perceptions of, general acceptance of, and likelihood of use of semen from the OPU-IVP-GS technology.

The questionnaire further prompted farmers on current breeding practices (secondary outcome measures), including the following: fertilization method, use of sexed semen, embryo transfer, genomic testing, and use of Nordic Total Merit (NTM). The NTM is a breeding index based on GS that focuses on many different traits related to production, including milk yield, fertility, udder health, feed, and leg health (Brøndum et al., 2015). It was developed by VikingGenetics, a Nordic cooperative breeding company through which most dairy cattle breeding in Denmark is coordinated. The questionnaire also included secondary outcome measures related to

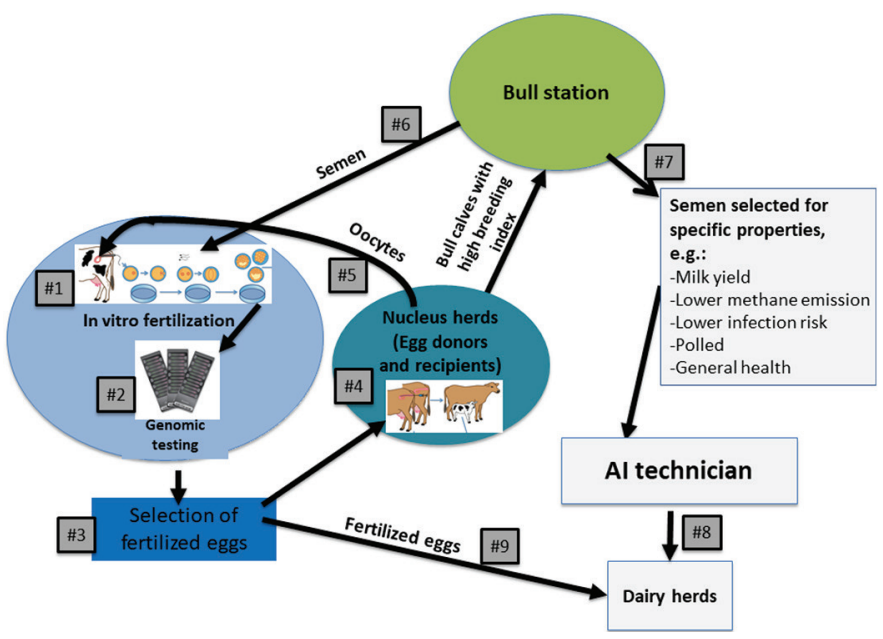

Figure 1. Presentation of the ovum pick-up-in vitro production of embryos-genomic selection technology and its application by end users to the participants in the survey (text in the figure has been translated to English from the Danish original). the following: how the farmers obtain information about breeding, who they communicate with about breeding, frequency of communication with breeding consultants, and their trust in the farm's primary breeding consultant.

The specific method presented to the farmers in this study to assess acceptance and the likelihood of adoption combined oocyte aspiration, Petri dish fertilization, the biopsying of embryos 6 to $7 \mathrm{~d}$ after fertilization, and GS. With reference to a figure (see Figure 1) with accompanying text, participants were introduced to the technology and the breeding improvement system more generally, and it was explained how they, as end users, could use the method. The figure and text were formulated to ensure that participants with potential (ethical) reservations about the technology were informed about all technological aspects involved, and to ensure that the likely potential of the technology was highlighted. Information about costs and other practical challenges of the technology were not included, as these factors are still unclear (given that technology is still not fully developed and marketable). Specifically, participants were given details of the IVP procedure, the genomic sequencing of fertilized eggs, and the way in which elite bulls and cows are used to improve traits; they were also told that the technology would speed up genetic progress. Further, they were provided with examples of specific traits that the breeding technology potentially could help improve in the future, namely the following: milk yield, lower methane gas emissions, lower risk of infection, polledness, and general health. Following this introduction, they were given several questions. The entire introductory text to the figure is available in Supplemental File S1. From their responses to these, we developed several outcome measures.

General Acceptance (Primary Outcome Measure 1). The following question was used for general acceptance: "As a matter of principle, do you think that it is alright to use this technology"? There were 6 response options: "No, absolutely not," "No," "Yes and no," "Yes," "Yes, absolutely," and "I am in doubt." Because the raw responses returned an unordered (qualitative) level variable, the responses were collapsed into 3 ordered categories: 1 (non-accept) = "No, absolute not" / "No"; 2 (undecided) = "Yes and no" / "I am in doubt," and 3 (acceptance) = "Yes" / "Yes, for sure" for use in multivariable analysis.

Likelihood of Use (Primary Outcome Measure 2). The question for likelihood of use was the following: "How likely is it that you will use semen from bulls from this breeding technology if, relative to the present breeding system, it improves the next generations of 
your herd in traits that you are aiming to improve?" Response options ranged from 1: "very unlikely" to 10: "very likely" (there was also a "don't know" option). To include the "don't know" responses in multivariable analysis, the responses were collapsed into 3 ordered categories: 1 (no or low likelihood) $=1,2,3,4,5$ and "Don't know;" 2 (high likelihood) $=6,7$, and 8; and 3 (very high likelihood) $=9$, and 10 .

Self-Reported Lack of Understanding. After the introduction to the technology, participants were asked to declare how well they understood the technology. Five response options ranging from "Not at all" to "To a high extent" were available to the participants. Responses were scored so that higher values indicated more lack of understanding as follows: 1 ("To a high extent") to 5 ("Not at all").

Perceived Utility. Perceived utility included 6 statements (developed by the authors) about different aspects of perceived utility. All were accompanied by the introductory text: "To what extent do you agree/ disagree with the following statement about the technology?" For example, "It is a relevant innovation" was one of the statements. Participants could respond on a scale from $1=$ "Strongly disagree" to $7=$ "Strongly agree" (a "don't know option" was available).

Ethical Reservations. We included 6 statements (developed by the authors) centering on ethical reservations. The introductory text and response options used for perceived utility were re-used. For example, "It is ethically problematic, because the technology could create monsters" was one of the statements.

\section{Statistical Analysis}

Descriptive statistics (either as means or proportions with 95\% CI) about breeding practices, information obtainment, and interpersonal communication about breeding were reported. Depending on variable types, $\chi^{2}$-tests, F-tests, or Spearman's rank correlation tests were used to identify demographic differences [i.e., production mode, farm size (number of dairy cows), and age of farmer] regarding the secondary outcome measures (breeding practices, and information obtainment/communication). In the cases of embryo transfer, we only examined age and farm size differences in the sample of conventional farmers. To account for multiple testing, Bonferroni-corrected $P$-values (Sedgwick, 2014) were calculated. Bonferroni correction for the examined breeding practice variables was 0.00833 (0.05 divided by 6 tests), and it was 0.0166 ( 0.05 divided by 3 tests) for information obtainment/communication variables. Frequencies were reported for the 2 main outcome variables, and for all single-item questions about perceived utility and ethical reservations.
Confirmatory factor analysis (CFA) was carried out using the sem command in Stata version 15.1 (StataCorp, 2013) to examine whether the statements on perceived utility and ethical reservations could be reduced to 2 underlying constructs for use in subsequent multivariable models. The results of the CFA showed that, when using 8 of the original 12 statements (4 perceived utility statements and 4 ethical reservations statements), 2 reliable measures could be produced $\left[\chi^{2}=25.57(\right.$ df: 19); Comparative Fit Index $=0.986 ;$ Tucker-Lewis Index $=0.979$; standardized root mean square residual $=0.045]$. The internal consistency of the 2 measures was also very good (Cronbach's $\alpha$ : perceived utility $=0.862$; ethical reservations $=0.812$ ) The 2 latent variables were denominated perceived utility $($ mean $=-0.003, \mathrm{SD}=1.327 ; \mathrm{n}=148)$ and ethical reservations $($ mean $=0.1013, \mathrm{SD}=1.322 ; \mathrm{n}=148)$, and higher scores on the variables indicated higher perceived utility and stronger ethical reservations, respectively. Eight participants were not assigned a score on the 2 measures because they responded "don't know" to more than 3 of the 12 statements about perceived utility and ethical reservations. "Don't know" does not belong to the same underlying continuum as the response options ranging from 1 ("completely disagree") to 7 ("completely agree"). For this reason, a participant with many "don't know" answers could not be meaningfully assigned a value on the underlying construct. See Supplemental File S2 (https://figshare.com/articles/ online_resource/SUPPLEMENTAL_FILE_S2_pdf/ 14387342) for details about the CFA.

For both of the primary outcomes, 2 ordered logistic regression models were used to identify statistically significant predictors. In model 1 , demographic variables [age, production mode, and farm size (number of dairy cows)] were inserted as predictor variables. In model 2 , current breeding practice variables, and variables reflecting perceptions of the OPU-IVP-GS technology (perceived utility, ethical reservations, lack of understanding) were added. If demographic predictors that were statistically significant in model 1 failed to retain this significance in model 2 , it was taken to imply that the demographic difference was explained by differences in breeding practices and technology perceptions.

Stata was used for the analysis. $P$-values were considered statistically significant at the 0.05 level. To account for the disproportional stratified random sampling design and a slight differential nonresponse regarding farm size, sample weights were calculated that adjusted the sample to the census (for dairy farms with at least 40 heifers/cows) on 2 variables: production type (organic vs. conventional) and farm size (Hibberts et al., 2012). All descriptive results (i.e., proportions and means) were weighted using Stata's svsyet command. 
Table 1. Comparison of sample and population census regarding farm size and region divided into the organic and conventional subsample ${ }^{1}$

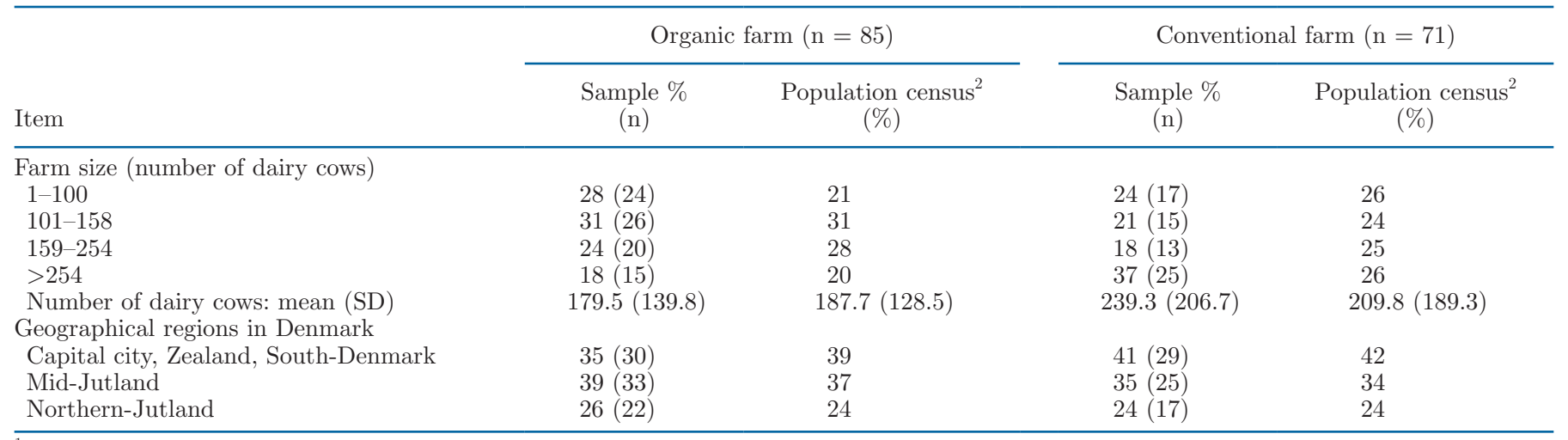

${ }^{1}$ Column percentages may in some cases not sum to 100 due to rounding error.

${ }^{2}$ The census consists of 2,752 dairy farm with at least 40 cows and heifers (per August 2018).

\section{RESULTS}

\section{Response Rate and Nonresponse Analysis}

In total, 156 farms completed the questionnaire: 85 organic and 71 conventional. After subtracting 18 farmers, who informed us they had ceased dairy production, we achieved a $41 \%$ response rate. The sample did not deviate from the general dairy farming population in regards to farm size (measured by number of dairy cows), and was examined separately for conventional $\left[\chi^{2}=4.73(\mathrm{df}: 3) ; P=\mathrm{NS}\right]$ and organic farmers $\left[\chi^{2}=\right.$ 2.93(df: 3); $P=$ NS]. Similarly, neither the conventional $\left[\chi^{2}=0.02(\mathrm{df}: 3) ; P=\mathrm{NS}\right]$ nor the organic sample $\left[\chi^{2}\right.$ $=0.51$ (df: 3$) ; P=\mathrm{SN}]$ deviated from the background population in geographical location (Danish regions) of the farm. See descriptive details in Table 1. We found that despite the moderate response rate, the sample quality is clearly acceptable.

\section{Breeding Practices, Information Obtainment, and Communication}

Table 2 reports the dairy farmers' breeding practices. It can be seen that AI is very widely used: $93 \%$ use this method. Sexed semen is also quite widespread, as $74 \%$ report using sexed semen routinely (and only $16 \%$ have never used it). Many farmers (55\%) report that they use semen from the NTM breeding index "to a high extent" or "to a very high extent." Embryo transfer is not widely used: $20 \%$ report using it "seldom," and only $3 \%$ "often/very often." Among conventional farmers, who are the only ones allowed to use embryo transfer, $23 \%$ report its use as "seldom," and $3 \%$ as "often/very often." Most farmers (66\%) agree that it is important to keep up with new breeding technologies.

Although various (noninterpersonal) information sources were used by the dairy farmers to obtain infor- mation about breeding (mean $=2.3$ ), the most popular source by far (at 71\%) was VikingNyt (see Table $3)$. This is a magazine produced by VikingGenetics (https://www.vikingdanmark.dk/da-dk/videncenter/ vikingnyt), the dominant Nordic supplier of cattle semen and breeding consultancy established in 2008 in the culmination of a long history of mergers in Danish and Nordic cattle breeding. A smaller proportion of farmers used newsletters/other magazines (42\%) and attended local meetings (34\%).

The farmers communicated with multiple people about breeding (mean $=2.6$ people during the last year). These were predominantly professionals [i.e., breeding consultants (69\%) and inseminators (64\%)]. The consultants were often from the breeding company VikingGenetics. Inseminators were typically also from the same company. Communication with other farmers (colleagues/friends: $36 \%$; or peer-to-peer groups: $20 \%$ ) and with close employees (28\%) was less common. On average, farmers consulted a breeding consultant (either by email, phone, or at a meeting) from the company they purchased most of their semen from 2.8 times per year. There was a high level of trust in breeding consultants: a large proportion of participants agreed that the specific consultant who advises them on breeding "is very competent" (67\%) and understands "the needs of the farm" $(67 \%)$.

\section{Demographic Differences}

Tests of association revealed that there was no difference between organic and conventional farmers regarding the current breeding practices laid out in Table 2 (i.e., sexed semen, semen from NTM, proportion of purebred cows genomically tested, and importance attached to keeping up with new breeding technologies). Similarly, there was no difference between organic and 
conventional farmers regarding the number of sources of information, number of people communicated with about breeding, and number of consultations with breeding consultants (see measures in Table 2). Tests of association revealed that self-reported idealistic organic farmers did not differ from conventional and other organic farmers in their current breeding practices and in their sources of information and interpersonal communication.

Size of dairy farm influenced use of advanced breeding technologies. It was positively correlated with use of sexed semen (Spearman's $\mathrm{r}=0.380 ; P<0.001$ ), NTM semen (Spearman's $\mathrm{r}=0.216 ; P<0.01$ ), genomic testing of purebred cows (Spearman's $\mathrm{r}=0.283$; $P<0.001$ ), and use of embryo transfer (only relevant for conventional farmers; $\mathrm{n}=71$; Spearman's $\mathrm{r}=0.237$; $P<0.05)$. After Bonferroni's correction for multiple testing, however, no significant differences were seen regarding use of the 2 latter mentioned technologies (i.e., genomic testing of purebred cows and embryo transfer). Farmers with larger farms communicated with a higher number of people (Spearman's $\mathrm{r}=0.371 ; P<0.001$ ) and used more sources of information (Spearman's $\mathrm{r}=$ 0.265; $P<0.001)$ about breeding. They also consulted a breeding consultant more frequently (Spearman's $\mathrm{r}=$ 0.464; $P<0.001)$.
There were also generational differences. Use of sexed semen declined with farmer age (Spearman's $\mathrm{r}=-0.186 ; P<0.05)$. However, after Bonferroni's correction for multiple testing this difference was not retained. Number of consultations with a breeding consultant declines with age (Spearman's $\mathrm{r}=-0.249$ ); $P$ $<0.01)$. Young farmers $(20-39 \mathrm{yr})$ consulted a breeding consultant on average 3.5 times per year $($ mean $=3.48$; $95 \% \mathrm{CI}=2.1-4.8$ ). This compares with 3 times (mean $=3.05 ; 95 \% \mathrm{CI}=1.9-4.2$ ) among middle-aged farmers $(40-59$ years $)$, and twice $($ mean $=1.77 ; 95 \% \mathrm{CI}=$ 1.0-2.5) among older farmers ( $>59 \mathrm{yr}$ ). The number of people that were communicated with about breeding exhibited the same pattern (Spearman's $\mathrm{r}=-0.313 ; P$ $<0.01$ ): young farmers communicated on average with 3.5 people $($ mean $=3.55 ; 95 \% \mathrm{CI}=2.8-4.3$ ), middleaged farmers communicated with less than 3 people (mean $=2.80 ; 95 \% \mathrm{CI}=2.4-3.2)$, and the oldest farmers with less than 2 people $($ mean $=1.94 ; 95 \% \mathrm{CI}=$ $1.6-2.3)$.

\section{General Acceptance and Likelihood of Using of the OPU-IVP-GS Technology}

Most the dairy farmers $(76 \% ; 95 \% \mathrm{CI}=66.1-84.3 \%)$ reported that they would use semen produced with the

Table 2. An overview of Danish dairy farmers' current breeding practices $(\mathrm{n}=156)^{1}$

\begin{tabular}{|c|c|c|}
\hline Item & $\begin{array}{c}\text { Percent of } \\
\text { farmers who } \\
\text { adopt practice }\end{array}$ & $95 \% \mathrm{CI}$ \\
\hline \multicolumn{3}{|l|}{ Fertilization method } \\
\hline AI & 93 & $86-97$ \\
\hline Other (including bull and other combinations) & 7 & $3-14$ \\
\hline \multicolumn{3}{|l|}{ Use of sexed semen } \\
\hline Never used (and no plan to use) & 16 & $10-26$ \\
\hline Used before (but not currently) & 10 & $5-18$ \\
\hline Uses it routinely & 74 & $63-82$ \\
\hline \multicolumn{3}{|l|}{ Use of the genetic index Nordic Total Merit } \\
\hline "Not at all" to "to some extent" & 45 & $34-55$ \\
\hline "To a high extent" / "To a very high extent" & 55 & $45-66$ \\
\hline \multicolumn{3}{|l|}{ Percent of purebred cows genomically tested } \\
\hline 0 (or don't know) & 52 & $41-62$ \\
\hline $1-79$ & 26 & $18-36$ \\
\hline $80-100$ & 22 & $15-32$ \\
\hline \multicolumn{3}{|l|}{ Use of embryo transfer } \\
\hline Never used (or more than $5 \mathrm{yr}$ ago) & 78 & $67-85$ \\
\hline Uses it, but seldom & 20 & $13-30$ \\
\hline Uses it often/very often & 3 & $1-8$ \\
\hline \multicolumn{3}{|c|}{ Importance attached to keeping up with new breeding technologies ${ }^{2}$} \\
\hline Farmer agrees it important to keep up & 66 & $55-75$ \\
\hline
\end{tabular}


aid of the OPU-IVP-GS technology: 27\% responded with 9 or 10 to the question about likelihood that they would use this kind of semen, which we interpreted as very likely use, and $50 \%$ responded with 6,7 , or 8 , which we interpreted as likely use (see Figure 2, upper part). Most the dairy farmers (61\%; $95 \%$ CI $=$ $50.1-70.9 \%$ ) deemed use of the technology acceptable: $41 \%$ responded "yes" and 20\% "yes, for sure" to the question "As a matter of principle, do you think that it is alright to use this technology?" (see Figure 2, lower part). A small proportion (6\%) had reservations about the technology and responded "no" or "no, absolutely not" to the same question. However, a quite large proportion $(33 \% ; 95 \%$ CI $=24.0-43.8 \%)$ was undecided and responded "yes and no" (27\%) or "I am in doubt" $(6 \%)$.

\section{Perceived Utility and Ethical Reservations}

The technology was perceived to have utility by most the dairy farmers (Table 4): $68 \%$ agreed (i.e., responded 5,6 , or 7 ) that the technology was a "relevant innovation" and $70 \%$ agreed that it is "very relevant if it does not become too expensive." A majority (61\%) also agreed that it could help dairy farmers "meet worries some members of the public have about the climate and environment," and that potentially it could "increase my surplus" (60\%). Just over half of the farmers (53\%) even thought of the technology as a "brilliant idea," and many (48\%) believed the technology necessary "in order to keep dairy farming economically sustainable."

Relatively few farmers had strong ethical reservations about the OPU-IVP-GS technology (see Table 4). Approximately 1 in 5 agreed (i.e., responded 5, 6, or 7) that the technology is worrying/ethically problematic because with it the speed of breeding refinement is "increased to an unnatural level" (15\%), because "fertilization should take place without human interference" (18\%), and because it "could create monsters" (18\%). A minority (26\%) agreed that the technology involves "too much laboratory work and too little farming." It should be noted, though, that many participants were undecided about the ethical aspects of the technology. Thus, between 32 and 40\% "neither disagree nor agree," and between 5 and $10 \%$ responded "don't know" to the statements. A much higher proportion (51\%) deemed

Table 3. Danish dairy farmers' sources of information and interpersonal communication about breeding (n $=156)^{1}$

\begin{tabular}{|c|c|c|}
\hline Item & $\begin{array}{l}\text { Percent of } \\
\text { farmers who } \\
\text { adopt practice }\end{array}$ & $95 \%$ CI \\
\hline \multicolumn{3}{|l|}{ Source of information } \\
\hline VikingNyt (Danish magazine about cattle breeding and reproduction) & 71 & $61-80$ \\
\hline Newsletters/other magazines received by email or post & 42 & $32-53$ \\
\hline Attending local meetings focusing on breeding & 34 & $25-44$ \\
\hline Follows lists to monitor how bulls match cows/heifers on the farm & 22 & $15-32$ \\
\hline Searches on different internet sites & 16 & $10-26$ \\
\hline Attending conferences focusing on cattle breeding & 9 & $5-16$ \\
\hline Other & 4 & $2-11$ \\
\hline Never procures new knowledge & 5 & $2-13$ \\
\hline Number of sources of information: mean & 2.3 & $2.0-2.6$ \\
\hline \multicolumn{3}{|l|}{ Interpersonal communication } \\
\hline Breeding consultants (from companies and associations) & 69 & $59-78$ \\
\hline Inseminators & 64 & $54-74$ \\
\hline Colleagues/friends that are dairy farmers & 36 & $27-47$ \\
\hline My closest employees & 28 & $20-38$ \\
\hline Salespersons from breeding companies & 26 & $18-37$ \\
\hline Colleagues in peer-to-peer groups & 20 & $13-29$ \\
\hline Close friends and family & 15 & $9-24$ \\
\hline Others & 3 & $1-9$ \\
\hline None of the mentioned & 4 & $1-11$ \\
\hline Number of people communicated with: mean & 2.7 & $2.4-3.0$ \\
\hline \multicolumn{3}{|l|}{ The breeding consultant; frequency of consultations and trust } \\
\hline Number of consultations with breeding consultant (year): mean & 2.8 & $2.0-3.5$ \\
\hline Agrees: that the consultant is very competent ${ }^{2}$ & 67 & $57-76$ \\
\hline Agrees: consultant has a good understanding of the needs of the farm ${ }^{2}$ & 67 & $56-76$ \\
\hline
\end{tabular}

${ }^{1}$ The reported means and shares are weighted so the results are representative for dairy farms in Denmark (see statistical analysis section for details).

${ }^{2}$ Response options ranged from 1 to 7 (1: "Completely disagree," 4: "Neither nor," 7: "Completely agree"), and 8 ("Don't know"). Responses 5, 6, and 7 were considered "agree" responses in the reported share of "agrees" in the table. 
the technology ethically unproblematic because it is "just a development from traditional breeding practices." Many (44\%) feared that "consumers could find the breeding technology ethically problematic and lose trust in dairy farmers."

\section{What Explains General Acceptance and Likelihood of Using the OPU-IVP-GS Technology?}

We first looked at nonadjusted associations between breeding practices and technology perceptions and the 2 outcomes (general acceptance and likelihood of use)-see Table 5. In general, use of modern breeding technologies (sexed semen, NTM semen, genomic testing of purebred cows), perceived importance of keeping up with new breeding technologies, and more consultations with breeding consultants were positively associated with general acceptance of the technology

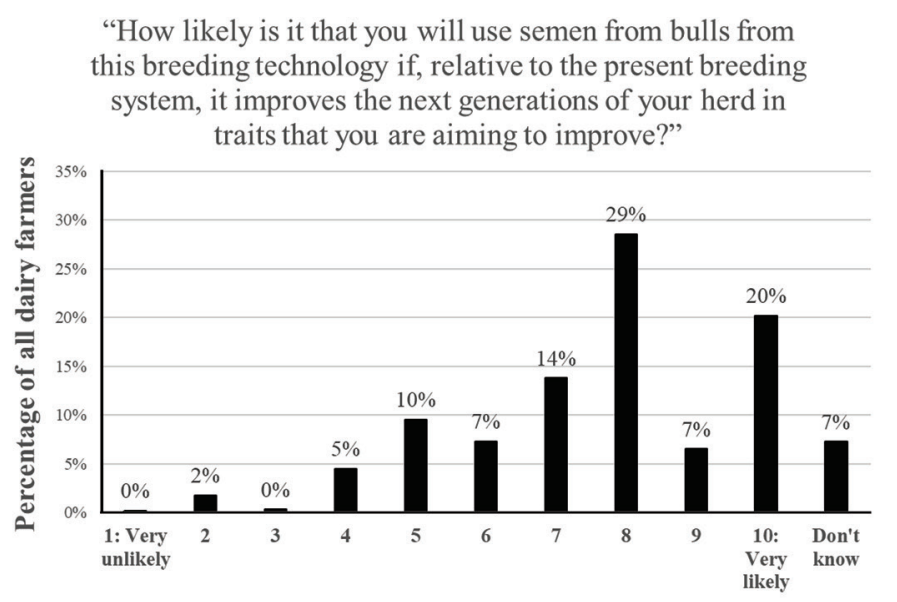

"As a matter of principle, do you think that it is all right to use this technology?"

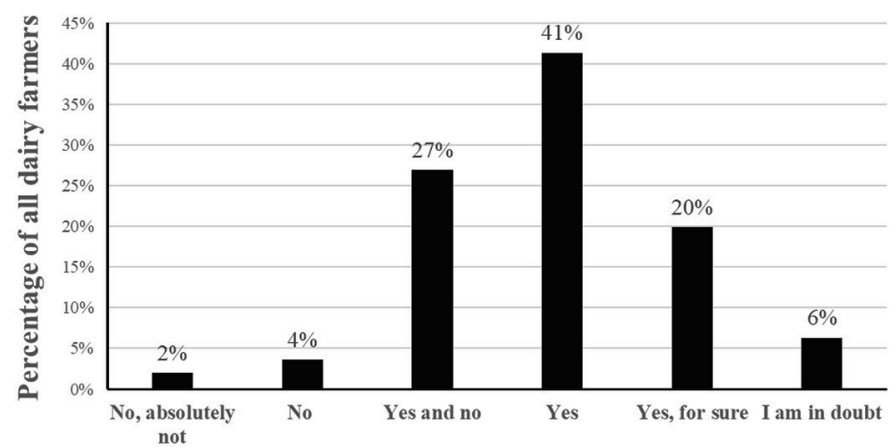

Figure 2. Likelihood of use of semen from, and general acceptance of, the ovum pick-up-in vitro production of embryos-genomic selection technology among Danish dairy farmers $(n=156$; the reported percentages are weighted so results are representative for dairy farms in Denmark). and higher likelihood of using it. Perceptions of the OPU-IVS-GS technology also have a large effect on acceptance and likelihood of use. Perceived utility was positively associated, and ethical reservations and selfreported lack of understanding of the technology were negatively associated, with general acceptance and likelihood of use.

When considering the multivariable analyses, starting with general acceptance (model 1 reported in the left-hand column in Table 6), all 3 demographic factors were significantly associated with general acceptance of the OPU-IVP-GS technology before adjustment for breeding practices and technology perceptions. Larger farms had higher acceptance of the technology than smaller farms (Spearman's $\mathrm{r}=0.203 ; P<0.05$ ). Acceptance of the technology was lower among self-reported idealistic organic farmers (see Figure 3, upper part): $31 \%$ of them responded "no" or "no, absolutely not" to the general acceptance question ("As matter of principle, do you think that it is alright to use this technology?") compared with 6 and $4 \%$ among other organic farmers and conventional farmers, respectively. Acceptance of the technology also decreased with age (Figure 3, lower part). Specifically, the youngest age cohort stood out: $83 \%$ of this group agreed that it is alright to use the technology.

In model 2 (in the left-hand column in Table 6) where variables relating to breeding practices and technology perceptions were added, only 2 of the variables reported in Table 5 remained statistically significant: namely perceived utility of the technology, which increased acceptance, and ethical reservations, which decreased acceptance. Model 2 also showed that lower age still predicted general acceptance of the technology, and the effects from farm size and production mode (specifically, self-reported idealistic organic farmers) were not statistically significant anymore. This indicated that the significant variables identified in model 2 (perceived utility and ethical reservations) explained farm size and production mode variation in acceptance.

In the multivariable analyses regarding likelihood of using semen from the technology, model 1 (reported in right-hand column of Table 6) did not identify differences between farm types (organic/conventional) and farmer's age in likelihood of use. However, larger farms were more likely to use semen from the technology than smaller farms (Spearman's $\mathrm{r}=0.326 ; P<0.001$ ). In model 2 (reported in right-hand column of Table 6), we found that likelihood of use increased in tandem with the frequency of current use of NTM semen and perceived utility. In contrast, self-reported lack of understanding of the OPU-IVP-GS technology decreased the likelihood of using the semen. Model 2 also showed farm size was no longer statistically significant. 
Table 4. Perceived utility of, and ethical reservations about, the ovum pick-up-in vitro production of embryos-genomic selection technology among Danish dairy farmers $(\mathrm{n}=156)^{1}$

\begin{tabular}{|c|c|c|c|c|c|c|c|c|}
\hline Item & $\begin{array}{c}1 \\
\text { Completely } \\
\text { disagree }\end{array}$ & 2 & 3 & $\begin{array}{c}4 \\
\text { Neither agree } \\
\text { nor disagree }\end{array}$ & 5 & 6 & $\begin{array}{c}7 \\
\text { Completely } \\
\text { agree }\end{array}$ & $\begin{array}{c}8 \\
\text { Don’t } \\
\text { know }\end{array}$ \\
\hline \multicolumn{9}{|l|}{ Perceived utility statement ( $\%$ of farmers for each response option $)^{2}$} \\
\hline $\begin{array}{l}\text { It is probably necessary in order to keep dairy farming economically } \\
\text { sustainable }\end{array}$ & 8 & 5 & 5 & 29 & 6 & 14 & 28 & 5 \\
\hline It is a relevant innovation & 2 & 3 & 3 & 21 & 15 & 13 & 40 & 3 \\
\hline Potentially, it can increase my surplus & 7 & 2 & 1 & 22 & 15 & 18 & 27 & 9 \\
\hline \multicolumn{9}{|l|}{$\begin{array}{l}\text { Ethical reservation statement } \\
(\% \text { of farmers for each response option })^{3}\end{array}$} \\
\hline $\begin{array}{l}\text { It is ethically worrying because the speed of breeding refinement } \\
\text { is increased to an unnatural level }\end{array}$ & 18 & 10 & 9 & 38 & 3 & 5 & 7 & 10 \\
\hline $\begin{array}{l}\text { It is ethically problematic, because fertilization should take place } \\
\text { without human interference }\end{array}$ & 28 & 8 & 6 & 36 & 10 & 3 & 5 & 5 \\
\hline $\begin{array}{l}\text { It is ethically unproblematic, because the technology is just } \\
\text { a development from traditional breeding practices }\end{array}$ & 4 & 5 & 4 & 32 & 9 & 13 & 29 & 5 \\
\hline
\end{tabular}

${ }^{1}$ The reported shares are weighted so the results are representative for dairy farms in Denmark (see Statistical Analysis section for details).

${ }^{2}$ The first 4 statements were used as items in the latent construct measuring perceived utility that is used in the subsequent analyses. See Supplemental File S2 (https://figshare.com/articles/online_resource/SUPPLEMENTAL_FILE_S2_pdf/14387342) for details.

${ }^{3}$ The first 4 statements were used as items in the latent construct measuring ethical reservations that is used in the subsequent analyses. See Supplemental File S2 for details.

\section{DISCUSSION}

Previous research that used diffusion theory (Rogers, 2003) to study dairy farmers examined how farm structural characteristics such as farm size, age, market position (Diederen et al., 2003), sources of information (Diederen et al., 2003), and social networks (Brown and Roper, 2017) affect propensity to adopt multiple novel

Table 5. Unadjusted associations (Spearman's rank correlation coefficients) between Danish dairy farmers' breeding practices and technology perceptions and general acceptance, and likelihood of use, of the ovum pickup-in vitro production of embryos-genomic selection technology (OPU-IVP-GS) technology ( $\mathrm{n}=148-156$ )

\begin{tabular}{lcc}
\hline Item & $\begin{array}{c}\text { General } \\
\text { acceptance }\end{array}$ & $\begin{array}{c}\text { Likelihood } \\
\text { of use }\end{array}$ \\
\hline Current breeding practices $^{1}$ & 0.150 & 0.126 \\
Uses AI $^{1}$ & $0.244^{* *}$ & $0.235^{* *}$ \\
Uses sexed semen $^{2}$ & $0.185^{*}$ & $0.459^{* *}$ \\
Frequency of use of NTM semen $^{3}$ & $0.245^{* *}$ & $0.378^{* * *}$ \\
Proportion of purebred cows genomically tested $^{4 *}$ & $0.361^{* * *}$ & $0.321^{* * *}$ \\
Important to keep up with new breeding technologies $^{5 *}$ & $0.253^{* *}$ & $0.274^{* * *}$ \\
Number of consultations with breeding consultant $_{\text {Perceptions of the OPU-IVP-GS technology }}$ & $0.591^{* * *}$ & $0.591^{* * *}$ \\
Perceived utility & $-0.511^{* * *}$ & $-0.557^{* * *}$ \\
Ethical reservations & $-0.247^{* *}$ & $-0.340^{* * *}$ \\
\hline Self-reported lack of understanding of the technology & & \\
\hline
\end{tabular}

${ }^{1}$ Binary variable (as in Table 2 ).

${ }^{2}$ Ordered variable with 3 values (as in Table 2 ).

${ }^{3}$ Ordered variable with 6 values ranging from "no use" to "a very high extent of use" of Nordic Total Merit (NTM) semen.

${ }^{4}$ Ordered variable with 11 values ranging from 0 to $100 \%$.

${ }^{5}$ Ordered response options ranging from 1 "strongly disagree" to 7 "strongly agree"

${ }^{*} P<0.05 ;{ }^{* *} P<0.01 ;{ }^{* * *} P<0.001 ; P$-values are from $t$-tests (as calculated by the spearman command in Stata v15.1; StataCorp, 2013). 


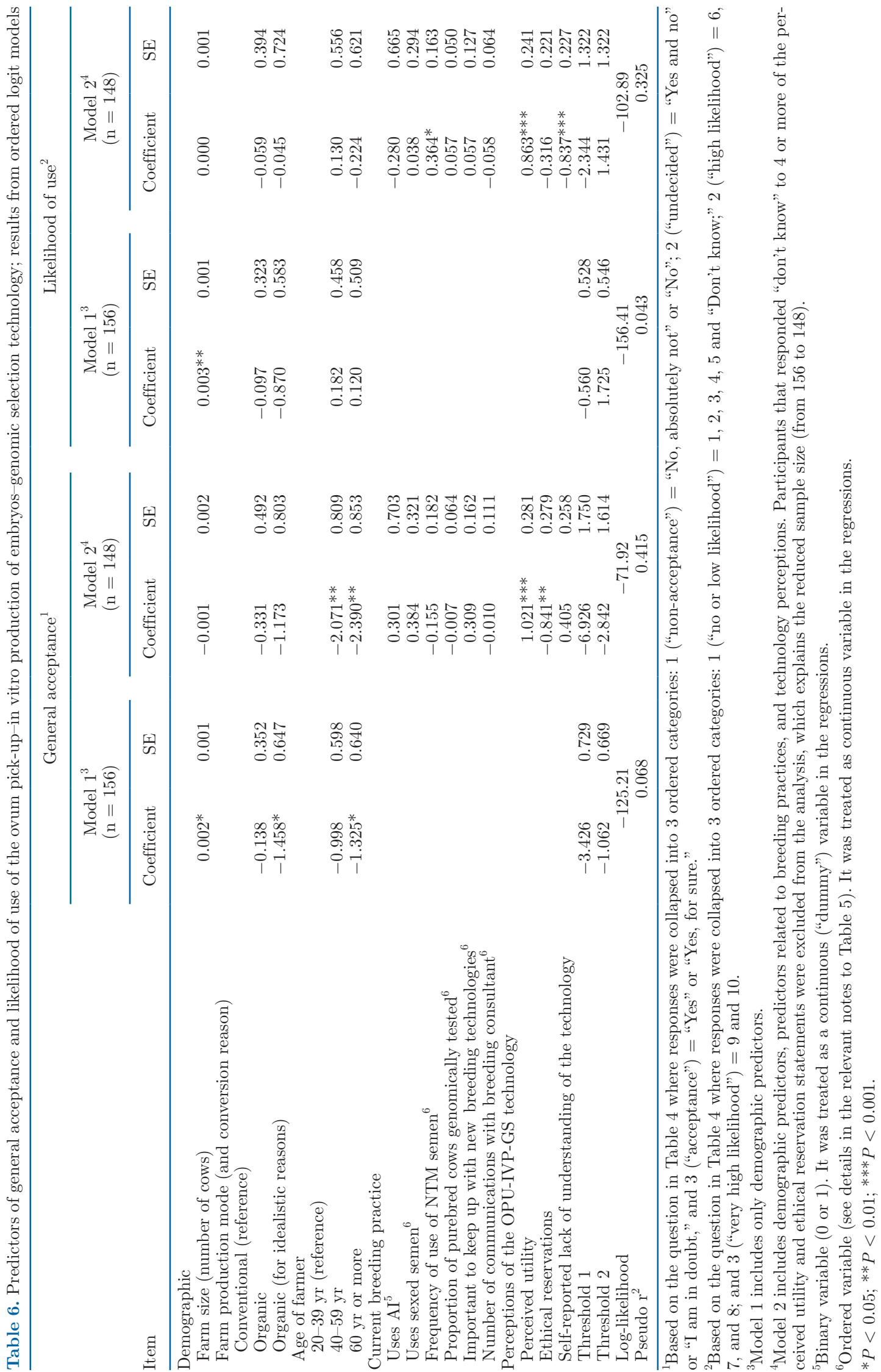


technologies that already exist. Our study is different in that only one novel technology was examined; furthermore, this technology was not marketed yet. However, the study is similar to the aforementioned studies in that many of the same explanatory factors were examined (farm characteristics and communication channels). We add to the literature by examining how acceptance and likelihood of use is shaped by the characteristics of an innovation (specifically, relative advantage and compatibility; Rogers, 2003), and by including multiple measures for communication channels (information obtainment, interpersonal communication, frequency of communication with and trust in breeding agents).

Our results suggest that the OPU-IVP-GS technology would be generally accepted and adopted by Danish dairy farmers, provided that there are no drawbacks to the technology, that there are clear breeding advantages, and that there is a reasonable pricing once it is marketed. Because the OPU-IVP-GS technology is not yet a fully implemented technology, and has not been
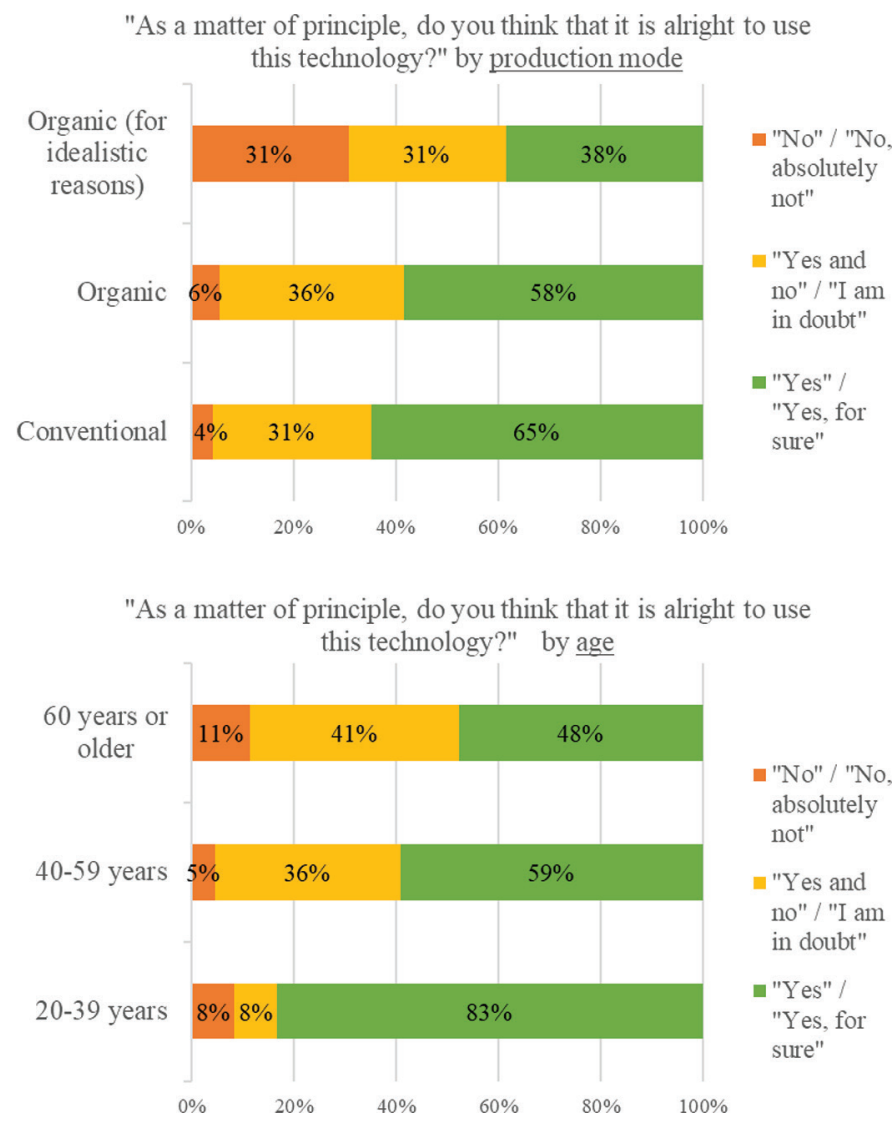

Figure 3. General acceptance of the ovum pick-up-in vitro production of embryos-genomic selection technology among Danish dairy farmers-reported as 100\% stacked bar graphs separately for age groups and production mode $(\mathrm{n}=156)$. discussed in the dairy farmer community, we cannot know for sure whether the relatively high level of support revealed in this study will be sustained in future. It is therefore important to consider possible arguments suggesting the opposite conclusion (i.e., low acceptance and limited use). Critical discussion of these arguments will serve as a background for a more robust assessment of the most likely future outcome.

Two arguments against acceptance and adoption of the new technology seem worthy of consideration. The first is a lack of information/persuasion argument. An innovation will not necessarily be adopted by users even if it provides clear advantages (Rogers, 2003). Specifically, it is only if the innovation becomes widely known, and if the flow of information between users, institutions, and influential actors is persuasive, that users adopt the technology. The second argument relies on the finding in this study that, in addition to farmers with ethical reservations about the OPU-IVP-GS technology, a substantial minority were unsure/undecided about the ethical acceptability of it. Persistent doubt of this kind could tip the balance toward rejection of the innovation if feelings of moral outrage (Antonetti and Maklan, 2016) at the technology become prevalent.

It is our belief that the results from this study deliver reasons to question these counter-arguments. The first argument, referring to lack of information and persuasion, is not very powerful given the highly developed communicative channels related to breeding observed in this study. Newsletter magazines and other resources devoted to breeding are readily available and also used by the majority of dairy farmers. The widespread use of AI means that most dairy farmers already communicate with inseminators, breeding consultants, and salespersons. Thus, there is no doubt that information about the OPU-IVP-GS technology will be widely disseminated. In addition, we have shown that farmers talk with breeding consultants (and salespersons) several times a year on average, and that the consultants are trusted by most farmers. Breeding consultants and salespersons represent specialized resource systems and promote innovations (Rogers, 2003). With frequent communication with change agents, there is a direct and active link between innovation institutions and end users. Persuasion to use semen from the OPU-IVP-GS technology will in practice be coupled with goal-directed discussion with consultants about the farms' breeding goals. This will arguably promote the perceived utility of the novel technology.

Several considerations also raise doubts about the force of the second argument, which turns on the risk of moral outrage. First, in the trade-off between ethical objections (e.g., excessively rapid progress, unnatural 
breeding methods, and risks) and farm utility (e.g., higher surplus, improved efficiency, meeting public demand), it seems likely that the advantages will outweigh potential worries when it comes to practical decisions over whether to use, or avoid using, the products emerging from applications of the technology. Clearly, farmers work in a competitive market where keeping up with other producers and products is central to survival. This need to keep pace can be addressed, among other things, through the improvements that breeding technology can provide. In support of this point, we refer to the statements about perceived utility, which were much more strongly agreed on by the farmers than the statements about ethical reservations. Indeed, many agreed (and only few disagreed) that the OPU-IVPGS technology is merely a development of traditional breeding methods, suggesting that the technology can be justified by referral to traditional breeding.

Second, structural developments in the Danish agricultural sector mean that farms are continuing to grow in size (Kaiser, 2015). Our study showed that large dairy farms (measured by number of cows) use modern breeding technologies (sexed semen, NTM semen, and genetic testing) to a greater extent than smaller farms. Farmers from larger farms also reported higher general acceptance and likelihood of using the OPU-IVP-GS technology. They did so because they perceived more utility and had lower ethical reservations. Third, the study results revealed intergenerational differences. A very large proportion of farmers in the youngest cohort found the technology acceptable. General acceptance was clearly lower in the 2 older cohorts. This means that general acceptance is likely to increase as the younger cohort take over dairy farms in Denmark.

Turning to organic farmers, we unexpectedly found that this group (excluding self-reported idealistic organic farmers) is as likely to accept the combined technology, and to use semen produced with it, as their conventional counterparts. Despite the original aim for naturalness of organic production and the attempts that have been made to develop specialized organic breeding systems (Nauta, 2009), our results reveal that organic farmers, at least in Denmark, are currently just as ready as conventional farmers to use semen produced on the basis of GS generally, and the novel technology studied in this paper specifically.

A possible explanation for this similarity between organic and conventional farmers could be an increased pragmatism among organic farmers. Earlier studies have identified substantial heterogeneity in the attitudes and goals of organic farmers (Darnhofer et al., 2005). Those who converted to organic production in later waves have been found to have more pragmatic pro-environmental views, and to be more likely to have converted in pursuit of higher revenue opportunities (Best, 2008; Noe, 2008; Constance and Choi, 2010). A recent study may reflect this pragmatism. In that study, it was found that organic dairy farmers in Denmark are even more strongly focused on breeding for improvements in production traits such as milk yield than conventional farmers (Slagboom et al., 2016). The fact that only $15 \%$ of organic farmers in our study cited purely idealistic reasons as their motivation to produce organically is another indication of the pragmatism at work. Although a larger share of self-reported idealistic organic farmers found use of the technology unacceptable (explained by a blend of ethical reservations and lack of perceived utility), this study found that this group is just as likely as other farmers to use sexed semen, AI, NTM semen, and genomic testing, and to report that they will use semen produced with the novel technology.

According to our findings, dairy farmers think of the OPU-IVP-GS technology as a means of addressing some of the ethical challenges in current dairy production. Most the surveyed farmers thought the technology could help meet public worries about animal welfare as well as climate change and other environmental issues. On the other hand, the farmers were well aware that the technological approach could backfire if consumers lose trust because they feel that the industry is going too far, technologically speaking. Indeed, the most widespread concern about the technology that we identified (one shared by almost half of the farmers) was this potential loss of consumer trust.

Of course, whether the technology will be found acceptable for use is not simply a matter of the views of its immediate users. In a wider perspective, it is very much a question of how the rest of society, including legislators, citizens, and consumers (Palmgren et al., 2015) regard it. The consumer's acceptance of agrifood technologies has been found to depend on perceptions of, and trade-offs between, benefit, risk, and what are referred to as other moral concerns (e.g., perceived lack of naturalness, authenticity, and threats to animal welfare; Van Kleef et al., 2007; Frewer et al., 2013; Frewer, 2017). Similar trade-offs recognized by members of the public have recently been identified in connection with genetic technologies applied to dairy cattle breeding (McConnachie et al., 2019; Ritter et al., 2019). Further studies are needed regarding public perceptions of the technology examined in this paper.

A limitation of our study was the $41 \%$ response rate. However, a low response rate is only problematic if there is nonresponse bias (Davern, 2013). Because the nonresponse analysis did not raise concerns, we expect 
nonresponse bias to be rather modest. Multiple tests of associations (i.e., multiplicity) were carried out between demographic measures and secondary outcome measures. This increases the risk of type 1 errors. However, we adjusted for this by reporting Bonferroni-corrected $P$-values (Sedgwick, 2014). Although the questionnaire was developed following qualitative interviews with farmers and pretesting of the questionnaire, the constructs in the questionnaire were not prevalidated before data collection. This may have affected the precision of the constructs, and hence the accuracy of the results. In particular, the measure used to categorize farmers as self-reported idealistic organic farmers should be treated with caution. Further, the specific traits that were highlighted to the participants as traits that semen from the technology could improve could have affected the proportion of farmers reporting likelihood of use. Other possible factors that could seriously impede use of the semen in the future include high costs and practical barriers such as incompatibility with current farm breeding systems. These factors were not examined in the paper, as the technology needs to be further developed before a study with realistic information on costs, possible breeding traits, and practical challenges can be carried out.

Our findings suggest that the Danish breeding industry can embark on research and development in the OPU-IVP-GS technology, as it is likely that there will be an uptake of semen from this technology-provided that costs are low and that breeding advantages are clear. However, a minority of farmers expressed ethical concerns, and although we suggested earlier in the discussion that this is unlikely to lead to widespread moral outrage and rejection of the technology, it is an important point of attention. Hence, we suggest the industry should engage in dialogue with dairy farmers to get a better understanding of their possible concerns. Our findings cannot be straightforwardly generalized to other countries for the obvious reason that salient characteristics of the dairy farm system in a given country will promote or inhibit acceptance and adoption of a technology. However, in developed countries, where there is fierce market competition, growth in farm size, a well-functioning extension system, and widespread use of GS, it is likely that acceptance and adoption will follow the trend identified in this study (i.e., that there will be an uptake). A potential inhibiting factor in some other countries could be failures in the efficient flow of communication between dairy farmers and professional breeding consultants. The high degree of communication between breeding professionals and farmers, and the farmers' widespread trust in consultants from the dominant dairy cattle breeding company (VikingGenetics), recorded in this study may depend on the fact that VikingGenetics is a nonprofit company owned collectively by the farmers themselves - an ownership arrangement not always found in other countries. Comparative studies are certainly needed to improve our understanding of this issue and the importance of market competition, farm size, current breeding practices, and communication channels.

\section{CONCLUSIONS}

It is likely that semen from the OPU-IVP-GS technology (and similar technologies) will be widely adopted in both conventional and organic farming provided that costs can be kept low, and there are advantages in terms of achieving desired breeding goals. In particular, the new generation of farmers appear to believe that use of the technology is acceptable, and economic incentives, and even ethical arguments, seem likely to favor adoption of the technology over time. Structural developments, with dairy farms continuing to grow in size, also seem to support the spread of the technology.

\section{ACKNOWLEDGMENTS}

The study presented in this paper was conducted as part of a large, strategic research project (funded by Innovation Fund Denmark (Aarhus, Denmark): 7045-00013B; and Danish Milk Levy Fund, Aarhus, Denmark) focusing on the OPU-IVP-GS technology. We thank the project partners for comments on our research design and an early version of the questionnaire. Partners include the private companies VikingGenetics, Trans Embryo Genetics, and EmbryoTrans Biotech. These partners had no role in conducting the study or in interpreting the results stemming from it. The authors have no other conflicts of interest to declare. We thank Just Jensen, Morten Kargo, Peter Løvendahl, and Jørn Rind Thomasen, all from the Center for Quantitative Genetics and Genomics, Aarhus University (Aarhus, Denmark), for help in understanding the effects on dairy cattle breeding of the technologies discussed here. We also want to thank Sara Kondrup (Department of Food and Resource Economics, University of Copenhagen, Copenhagen, Denmark), for help with a literature search, Paul Robinson (Verbor Editorial Services, Bath, United Kingdom), for language editing, and 2 anonymous referees for very useful critical comments.

\section{REFERENCES}

Antonetti, P., and S. Maklan. 2016. An extended model of moral outrage at corporate social irresponsibility. J. Bus. Ethics 135:429444. https://doi.org/10.1007/s10551-014-2487-y.

Behboodi, E., G. B. Anderson, R. H. BonDurant, S. L. Cargill, B. R. Kreuscher, J. F. Medrano, and J. D. Murray. 1995. Birth of 
large calves that developed from in vitro-derived bovine embryos. Theriogenology 44:227-232. https://doi.org/10.1016/0093 $-691 \mathrm{X}(95) 00172-5$.

Best, H. 2008. Organic agriculture and the conventionalization hypothesis: A case study from West Germany. Agric. Human Values 25:95-106. https://doi.org/10.1007/s10460-007-9073-1.

Brøndum, R. F., G. Su, L. Janss, G. Sahana, B. Guldbrandtsen, D. Boichard, and M. S. Lund. 2015. Quantitative trait loci markers derived from whole genome sequence data increases the reliability of genomic prediction. J. Dairy Sci. 98:4107-4116. https://doi.org/ 10.3168/jds.2014-9005.

Brooks, K. R., and J. L. Lusk. 2011. U.S. consumers attitudes toward farm animal cloning. Appetite 57:483-492. https://doi.org/ 10.1016/j.appet.2011.06.014.

Brown, P., and S. Roper. 2017. Innovation and networks in New Zealand Farming. J. Agric. Resour. Econ. 61:422-442. https://doi .org/10.1111/1467-8489.12211.

Chastant-Maillard, S., H. Quinton, J. Lauffenburger, N. CordonnierLefort, C. Richard, J. Marchal, P. Mormede, and J. P. Renard. 2003. Consequences of transvaginal follicular puncture on well-being in cows. Reproduction 125:555-563. https://doi.org/10.1530/ rep.0.1250555.

Coles, D., L. Frewer, and E. Goddard. 2015. Ethical issues and potential stakeholder priorities associated with the application of genomic technologies applied to animal production systems. J. Agric. Environ. Ethics 28:231-253. https://doi.org/10.1007/s10806 -015-9529-z.

Collins, D. 2003. Pretesting survey instruments: An overview of cognitive methods. Qual. Life Res. 12:229-238. https://doi.org/10 .1023/A:1023254226592.

Constance, D. H., and J. Y. Choi. 2010. Overcoming the barriers to organic adoption in the United States: A look at pragmatic conventional producers in Texas. Sustainability 2:163-188. https://doi .org/10.3390/su2010163.

Dan, V., A. Osterheider, and J. Raupp. 2019. The diffusion of innovations in agricultural circles: An explorative study on alternative antimicrobial agents. Sci. Commun. 41:3-37. https://doi.org/10 $.1177 / 1075547018819159$.

Darnhofer, I., W. Schneeberger, and B. Freyer. 2005. Converting or not converting to organic farming in Austria: farmer types and their rationale. Agric. Human Values 22:39-52. https://doi.org/10 .1007/s10460-004-7229-9.

Davern, M. 2013. Nonresponse rates are a problematic indicator of nonresponse bias in survey research. Health Serv. Res. 48:905-912. https://doi.org/10.1111/1475-6773.12070.

de Haas, Y., M. Pszczola, H. Soyeurt, E. Wall, and J. Lassen. 2017. Invited review: Phenotypes to genetically reduce greenhouse gas emissions in dairying. J. Dairy Sci. 100:855-870. https://doi.org/ 10.3168 /jds.2016-11246.

Diederen, P., H. V. Meijl, A. Wolters, and K. Bijak. 2003. Innovation adoption in agriculture: Innovators, early adopters and laggards. Cahiers d'Economie et Sociologie Rurales 67:29-50. https://doi .org/10.22004/ag.econ.205937.

European Union. 2007. COUNCIL REGULATION (EC) No 834/2007 of 28 June 2007 on organic production and labelling of organic products and repealing Regulation (EEC) No 2092/91. Accessed Jun. 20, 2020. https://eur-lex.europa.eu/LexUriServ/LexUriServ .do?uri=CONSLEG:2007R0834:20130701:EN:PDF

Frewer, L. J. 2017. Consumer acceptance and rejection of emerging agrifood technologies and their applications. Eur. Rev. Agric. Econ. 44:683-704. https://doi.org/10.1093/erae/jbx007.

Frewer, L. J., I. A. van der Lans, A. R. H. Fischer, M. J. Reinders, D. Menozzi, X. Zhang, I. van den Berg, and K. L. Zimmermann. 2013. Public perceptions of agri-food applications of genetic modification-A systematic review and meta-analysis. Trends Food Sci. Technol. 30:142-152. https://doi.org/10.1016/j.tifs.2013.01.003.

Hansen, P. J. 2020. Implications of assisted reproductive technologies for pregnancy outcomes in mammals. Annu. Rev. Anim. Biosci. 8:395-413. https://doi.org/10.1146/annurev-animal-021419 -084010 .
Hibberts, M., R. B. Johnson, and K. Hudson. 2012. Common survey sampling techniques. Pages 53-74 in Handbook of Survey Methodology for The Social Sciences. L. Gideon, ed. Springer.

Howley, P., C. Donoghue, and K. Heanue. 2012. Factors affecting farmers' adoption of agricultural innovations: A panel data analysis of the use of artificial insemination among dairy farmers in Ireland. J. Agric. Sci. 4:171-179. https://doi.org/10.5539/jas.v4n6p171.

Humblot, P., D. Le Bourhis, S. Fritz, J. J. Colleau, C. Gonzalez, C. Guyader Joly, A. Malafosse, Y. Heyman, Y. Amigues, M. Tissier, and C. Ponsart. 2010. Reproductive technologies and genomic selection in cattle. Vet. Med. Int. 2010:19287. https://doi.org/10 $.4061 / 2010 / 192787$.

Kaaya, H., B. Bashaasha, and D. Mutetikka. 2005. Determinants of utilisation of artificial insemination (AI) services among Ugandan dairy farmers. Pages 561-567 in African Crop Science Conference Proceedings.

Kaiser, K. 2015. Landbrugets Strukturudvikling 2014-2022. SEGES. Presentation at Kommunernes Landsforening October 9, 2015. Accessed Jun. 20, 2020. https://www.kl.dk/media/12985/ 15lxxcnrs4f4f5d-97a8.pdf.

Kasinathan, P., H. Wei, T. Xiang, J. A. Molina, J. Metzger, D. Broek, S. Kasinathan, D. C. Faber, and M. F. Allan. 2015. Acceleration of genetic gain in cattle by reduction of generation interval. Sci. Rep. 5:8674. https://doi.org/10.1038/srep08674.

Khanal, A.R., J. M. Gillespie, and J. MacDonald. 2010. Adoption of technology, management practices, and production systems in US milk production. J. Dairy Sci. 93:6012-6022. https://doi.org/10 $.3168 /$ jds.2010-3425.

Mark, T., and P. Sandøe. 2010. Genomic dairy cattle breeding: Risks and opportunities for cow welfare. Anim. Welf. 19:113-121.

McConnachie, E., M. J. Hötzel, J. A. Robbins, A. Shriver, D. M. Weary, and M. A. G. von Keyserlingk. 2019. Public attitudes towards genetically modified polled cattle. PLoS One 14:e0216542. https: /doi.org/10.1371/journal.pone.0216542.

Miljø- og Fødevareministeriet. 2014. LBK nr 478 af 15/05/2014. Bekendtgørelse af lov om kloning og genmodificering af dyr m.v. Accessed Nov. 2, 2020. https://www.retsinformation.dk/eli/lta/ $2014 / 478$.

Nauta, W. 2009. Selective breeding in organic dairy Production. PhD Thesis. Wageningen Institute of Animal Science, Wageningen University, Wageningen, the Netherlands.

Noe, E. 2008. Drivkræfter og barrierer for omlægning til økologisk jordbrug set ud fra et sociologisk perspektiv. Pages 273-289 in Udvikling, vækst og integritet i den danske $\varnothing$ kologisektor. H. F. Alrøe, and N. Halberg, ed. ICROFS-rapport nr. 1/2008.

Olum, S., X. Gellynck, J. Juvinal, D. Ongeng, and H. De Steur. 2019. Farmers' adoption of agricultural innovations: A systematic review on willingness to pay studies. Outlook Agric. 49:187-203. https:// doi.org/10.1177/0030727019879453.

Palmgren, M. G., A. K. Edenbrandt, S. E. Vedel, M. M. Andersen, X. Landes, J. T. Østerberg, J. Falhof, L. I. Olsen, S. B. Christensen, P. Sandøe, C. Gamborg, K. Kappel, B. J. Thorsen, and P. Pagh. 2015. Are we ready for back-to-nature crop breeding? Trends Plant Sci. 20:155-164. https://doi.org/10.1016/j.tplants.2014.11.003.

Ponsart, C., D. Le Bourhis, H. Knijn, S. Fritz, C. Guyader-Joly, T. Otter, S. Lacaze, F. Charreaux, L. Schibler, D. Dupassieux, and E. Mullaart. 2013. Reproductive technologies and genomic selection in dairy cattle. Reprod. Fertil. Dev. 26:12-21. https://doi.org/10 .1071/RD13328.

Ritter, C., A. Shriver, E. McConnachie, J. Robbins, M. A. G. von Keyserlingk, and D. M. Weary. 2019. Public attitudes toward genetic modification in dairy cattle. PLoS One 14:e0225372. https://doi .org/10.1371/journal.pone.0225372.

Robinson, O. 2014. Sampling in interview-based qualitative research: A theoretical and practical guide. Qual. Res. Psychol. 11:25-41. https://doi.org/10.1080/14780887.2013.801543.

Rogers, E. M. 2003. Diffusion of Innovations. Free Press.

Ryan, B., and N. Gross. 1943. The diffusion of hybrid seed corn in two Iowa communities. Rural Sociol. 8:15-24. 
Schaeffer, L. R. 2006. Strategy for applying genome-wide selection in dairy cattle. J. Anim. Breed. Genet. 123:218-223. https://doi.org/ 10.1111/j.1439-0388.2006.00595.x.

Sedgwick, P. 2014. Multiple hypothesis testing and Bonferroni's correction. BMJ 349:g6284. https://doi.org/10.1136/bmj.g6284.

Slagboom, M., M. Kargo, D. Edwards, A. C. Sørensen, J. R. Thomasen, and L. Hjortø. 2016. Organic dairy farmers put more emphasis on production traits than conventional farmers. J. Dairy Sci. 99:9845-9856. https://doi.org/10.3168/jds.2016-11346.

StataCorp. 2013. Stata Structural Equation Modeling Reference Manual - Release 13. Stata Press.

Thomasen, J. R. A., A. Willam, C. Egger-Danner, and A. C. Sørensen. 2016. Reproductive technologies combine well with genomic selection in dairy breeding programs. J. Dairy Sci. 99:1331-1340. https: //doi.org/10.3168/jds.2015-9437.

Van Kleef, E., J. R. Houghton, A. Krystallis, U. Pfenning, G. Rowe, H. Van Dijk, I. A. Van der Lans, and L. J. Frewer. 2007. Consumer evaluations of food risk management quality in Europe. Risk Anal. 27:1565-1580. https://doi.org/10.1111/j.1539-6924.2007.00989.x.

Verhoog, H. 2003. Naturalness and the genetic modification of animals. Trends Biotechnol. 21:294-297. https://doi.org/10.1016/ S0167-7799(03)00142-2.
Viana, J. 2019. 2018 Statistics of embryo production and transfer in domestic farm animals. Pages 1-26 in Embryo Technology Newsletter 36. International Embryo Technology Society.

Walton, M. 2018. Commercial applications of SCNT in livestock. Pages 21-35 in Animal Biotechnology 2. Niemann H., and C. Wrenzycki, ed. Springer.

Windig, J. J., R. A. Hoving-Bolink, and R. F. Veerkamp. 2015. Breeding for polledness in Holstein. Livest. Sci. 179:96-101. https://doi .org/10.1016/j.livsci.2015.05.021.

Wrenzycki, C. 2018. In vitro Production of (Farm) Animal Embryos. Pages 269-304 in Animal Biotechnology 1: Reproductive Biotechnologies. Niemann H, and C. Wrenzycki, ed. Springer, 2018.

\section{ORCIDS}

T. B. Lund ๑ https://orcid.org/0000-0001-5282-1562

C. Gamborg @ https://orcid.org/0000-0003-3150-8280

J. Secher (ํ) https://orcid.org/0000-0002-7399-7142

P. Sandøe (1) https://orcid.org/0000-0003-0397-3273 